\title{
Chemical composition of essential oil from leaves of seeded and seedless Citrus reticulata blanco var. kinnow
}

\author{
Z. Parveen*, S. Siddique and Z. Ali \\ PCSIR Laboratories Complex, Ferozpur Road Lahore-54600, Pakistan
}

\begin{abstract}
The hydro-distilled essential oil of Citrus reticulata Blanco var. kinnow was analyzed by Gas chromatography-mass spectrometry (GC-MS). Five constituents out of fifteen constituents were identified from seeded C. reticulata oil representing $74.66 \%$ of the oil. The major constituent of the oil was $\beta$ - phellandrene $(62.00 \%)$. $\beta$-pinene $(6.53 \%), \beta$-myrcene $(2.81 \%)$, limonene $(2.81 \%)$ and caryophyllene $(0.51 \%)$ were present in considerable amount. From the low seeded $C$. reticulata oil, six components out of seventeen compounds were identified constituting $54.74 \%$ of the oil and the main component was $\beta$-phellandrene (37.35\%). $\alpha$-pinene(2.79\%), $\beta$-pinene(3.26\%), $\beta$-myrcene(4.16\%), limonene(5.77\%), caryophyllene(1.41\%) were present in considerable amount.
\end{abstract}

Keywords: Citrus reticulata Blanco; Kinnow; Essential oil; Gas chromatography-mass spectrometry

\section{Introduction}

C. reticulata Blanco var. kinnow belongs to genus Citrus of the Rutaceae or Rue family, which comprises of about 140 genera and 1,300 species (Singh et. al., 1983; Anwar et. al., 2008). Citrus are well known as one of the world's major fruit crops that are produced in many countries with tropical or subtropical climate. Brazil, USA, Japan, China, Mexico, Pakistan, and countries of the Mediterranean region, are the major Citrus producers. With the development of the processing industry and the demand for higher quality fruit, the production of fruits with few or no seeds has steadily increased (Ye et.al., 2009). Seedlessness is an important economic trait relating to fruit quality. There are many desirable characteristics of seedless fruit, which include high quality and taste, which are greatly valued by both consumers and the processing industry. The presence of a large number of seeds in citrus fruits greatly hinders consumer acceptability, even if it has good organoleptic properties. Therefore, the development of seedless fruit cultivars has become a major goal for fruit breeders around the world and different approaches have been adopted by numerous researchers (Raza et. al., 2003, and Yamamoto et. al., 1995)

Citrus fruits are used for dessert, juice and jam production as well as they have important economic value for their essential oils (Fisher and Phillips, 2008; Anwar, 2008). The essential oils are composed of many compounds including: terpenes, sesquiterpenes, aldehydes, alcohols, esters and sterols. They may also be described as mixtures of hydrocarbons, oxygenated compounds and nonvolatile residues. Primarily, they are used as aroma flavour in many food products, including alcoholic and nonalcoholic beverages, marmalades, gelatins, sweets, soft drinks, ice creams, dairy products, candies, and cakes (Steuer et. al., 2001; Campi et. al.,2009). They can also serve as an excellent starting material in the synthesis of fine chemicals and of new fragrances for the cosmetic industry (Lis-Balchin, 1999). Moreover, citrus essential oils have been recognized as safe due to their wide spectrum of biological activities such as antimicrobial, anti-inflammatory and antioxidant, (Fisher and Phillips, 2008). (Chutia et. al., 2009) (Rehman, 2006). Due to their great nutraceutical and economic importance, numerous investigations have been performed aiming at identifying the chemical composition, antimicrobial activities of the essential oils from peel of different citrus species. But there is no much data on the essential oil of $C$. reticulata (seeded and seedless) leaves.

The aim of this study is to determine the chemical composition of essential oil of seeded and seed less kinnow leaves.

\section{Materials and methods}

\section{Extraction of essential oil}

The fresh leaves of seeded and seedless $C$. reticulata were collected from NIAB, Faisalabad and subjected to hydro-distillation by using Dean-Stark assembly (Sattar, 
1989). The distillate were removed and separated from water by using a separating funnel. Oils were dried over anhydrous sodium sulphate and stored in a refrigerator until further analysis.

\section{GC-MS analysis}

The analysis of the essential oil was carried out on gas chromatography/mass spectrometry (GC-MS) of Agilent Technologies Inc., USA, Model 6890N, operating in electron ionization mode at $70 \mathrm{eV}$ equipped with a split-less injector. Helium was used as a carrier gas at the flow rate of $1 \mathrm{ml} / \mathrm{min}$, while DB-5 (30 $\mathrm{m} \times 0.25 \mathrm{~mm}$ id, $0.25 \mu$ film thickness $)$ capillary column was used. The initial temperature was programmed at $50-140^{\circ} \mathrm{C}$ at the rate of $5^{\circ} \mathrm{C} / \mathrm{min}$ and then $100-250^{\circ} \mathrm{C}$ at the rate of $3^{\circ} \mathrm{C} / \mathrm{min}$ followed by a constant temperature at $260^{\circ} \mathrm{C}$ for a period of $20 \mathrm{~min}$. Sample $(2 \mu \mathrm{l})$ was injected to column programmed at $200^{\circ} \mathrm{C}$ and resolutions of components were attained. The mass spectrometer is capable of scanning from 35 to 500 AMU every second or less. The data acquisition system continuously acquires and stores all data analyses. The components were identified by their retention time and peak enhancement with standard samples in GC mode and NIST library search from the derived fragmentation pattern of the various components of the oil.

\section{Results and Discussion}

The essential oil was extracted by hydro-distillation from the leaves of seeded and seedless $C$. reticulata; the yield was $0.11 \%$ and $0.03 \%(\mathrm{v} / \mathrm{w})$ respectively. The gas chromatography coupled with mass spectrometry revealed the presence of 15 components in seeded C. reticulata and 17

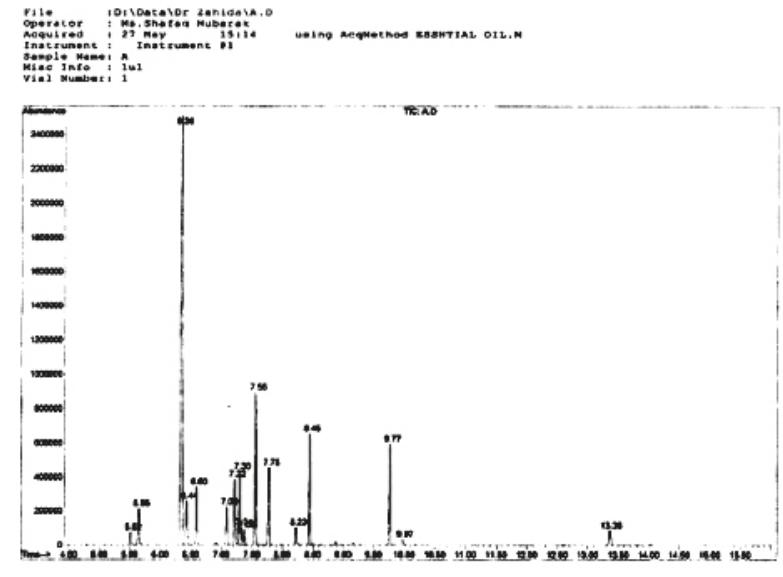

Time (minutes)

Fig. 1. Chromatogram of seeded $C$. reticulata Blanco leaves essential oil

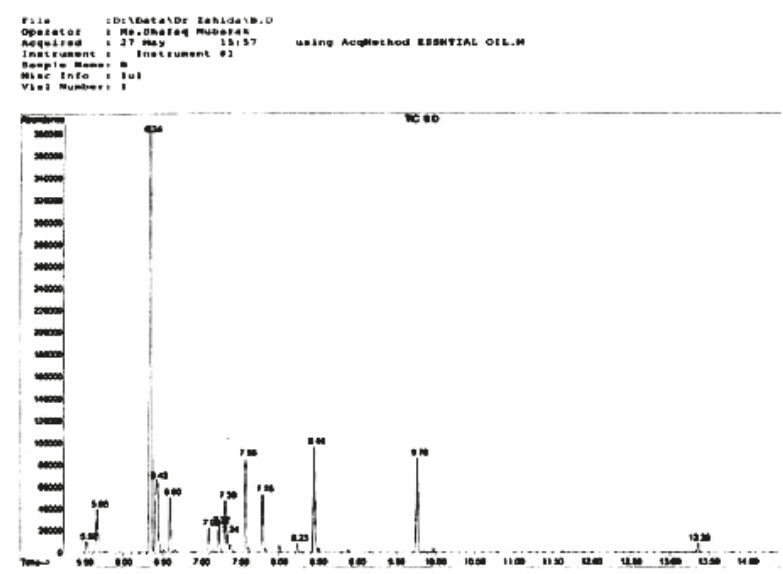

Time (minutes)

Fig. 2. Chromatogram of seedless $C$. reticulata Blanco leaves essential oil

Table I. Volatile Constituents of seeded and seedless $C$. reticulata Blanco leaves essential oil

\begin{tabular}{|c|c|c|c|c|c|}
\hline \multirow{2}{*}{$\begin{array}{l}\text { Sl. } \\
\text { No. }\end{array}$} & \multirow{2}{*}{$\begin{array}{l}\text { Name of } \\
\text { components }\end{array}$} & \multirow{2}{*}{$\begin{array}{l}\text { Retention } \\
\text { time (min.) }\end{array}$} & \multicolumn{2}{|c|}{ Percentage $(\%)$} & \multirow{2}{*}{ m/e Values(\%) } \\
\hline & & & Seeded & Seedless & \\
\hline 1 & $\alpha$ - pinene & 5.654 & -- & 2.79 & 136(M+1,8), 121(17),105(13), 93(100), 80(6), 77(31), 67(6), 65(6), 55(6), 53(8) \\
\hline 2 & $\beta$ - phellandrene & 6.346 & 62.00 & 37.35 & 136( $\left.\mathrm{M}^{+}, 19\right), 121(7), 93(100), 77(35), 80(11), 69(8), 65(7), 53(6)$ \\
\hline 3 & $\beta$ - pinene & 6.438 & 6.53 & 3.26 & 136( $\left.\mathrm{M}^{+}, 5\right), 121(8), 107(4), 93(100), 79(19), 65(7), 53(10), 50(3)$ \\
\hline 4 & $\beta$-myrcene & 6.598 & 2.81 & 4.16 & 136(M+1 $\left.\mathrm{M}^{+}, 5\right), 121(6), 107(3), 93(100), 79(18), 69(70), 53(12)$ \\
\hline 5 & Limonene & 7.302 & 2.81 & 5.77 & 154(M+39),139(28),134(29),119(100),108(34),93(24),81(32), 71(20), 55(15) \\
\hline 6 & Caryophyllene & 13.361 & 0.51 & 1.41 & $\begin{array}{l}204\left(\mathrm{M}^{+}, 9\right), 189(29), 175(15), 161(41), 147(33), 133(100), 120(43), 115(8), 109(19), \\
105(58) 93(86), 79(68), 69(56), 65(18), 55(25), 51(6)\end{array}$ \\
\hline
\end{tabular}


compounds in seedless $C$. reticulata, out of which five and six components were identified from seeded and seedless $C$. reticulata respectively (Table I) and (Figs. $1 \& 2$ ).

Only monoterpene hydrocarbons are present in leaves oil of $C$. reticulata and among the monoterpene hydrocarbons, $\beta$-phellandrene is predominant in both cultivars $(62 \%$ and $37 \%$ ). This result is contrary to previous results in which sabinene, linalool, $\gamma$-terpinene and methyl $\mathrm{N}$-methylanthranilate were observed as major constituents in C. reticulata leaf oils (Olusegun, 1990, Marie-Laure et.al., 2000; Darjazi, 2012). To our knowledge, this is the first time reporting of $\beta$ phellandrene as major constituent of $C$. reticulate leaf oil. $\beta$-phellandrene is widely used in perfumes and artificial essential oils because of its peppery, minty, refreshing, and slightly citrusy odor. Also, $\beta$-phellandrene finds importance as an intermediate in various synthesis schemes, such as in the preparation of 1-menthol.

$\alpha$ - pinene is absent in seeded $C$. reticulata while in seedless cultivar it is present in appreciable concentrations $(2.79 \%)$. Limonene which is the chief constituent (75-95\%) in about all the peels and leaves essential oil of local varieties of citrus species of Pakistan (Saima et. al., 2012; Ghulam et. al., 2013; Shabnam et. al., 2014 ) was present in very low concentration, $2.81 \%$ and $5.775 \%$ in seeded and seedless $C$. reticulata oil respectively. $\quad \beta$-pinene, $\beta$-myrcene, caryophyllene were present in considerable amount in both cultivars. These results are in good agreements with previous studies in which, $\beta$-pinene, and $\alpha$-pinene were present in appreciable concentrations in $C$. reticulata cultivar leaf oil (Adeleke et. al., 2010; Darjazi, 2011; Darjazi, 2012).

\section{Conclusion}

The results of our present study showed the essential oil from leaves of of $C$. reticulata var. kinnow rich in monoterpene hydrocarbons and can be utilized in food, beverages and perfumery.

\section{Acknowledgments}

The authors are grateful to Dr. Zia ur Rehman, Senior Scientific Officer, PCSIR Laboratories Complex, Ferozpur Road, Lahore-54600, Pakistan for GC-MS analysis.

\section{References}

Anwar F, Naseer R, Bhanger M I, Ashraf S, Talpur F N and Aladedunye: F A (2008), Physico-Chemical Characteristics of Citrus Seeds and Seed Oils from Pakistan, J Am Oil Chemist Soc. 85: 321-330.
Adeleke A K, Oladipupo A L, Olatunji T F A, Abayomi AO and William NS (2010), Citrus Essential Oils of Nigeria Part IV: Volatile Constituents of Leaf Oils of Mandarins (Citrus reticulata Blanco) From Nigeria, Rec Nat Prod. 4(3): 156-162.

Campi E M, Roy Jackson W, Patti A F (2009), Effect of oxidative deterioration on flavour and aroma components of lemon oil, Food Chem. 112(2): 388-393.

Chutia M, Bhuyan P D, Pathak M G, Sharma T C and Boruah $P$ (2009), Antifungal activity and chemical composition of Citrus reticulata Blanco essential oil against phytopathogens from North East India, Food Sci Technol. 42: 777-780.

Darjazi B B (2012), A comparison of volatile components of flower, leaf and peel of Citrus reticulata Blanco (Citrus nobilis Lour var. deliciosa swingle), J Med Plants Res. 6(12): 2365-2372.

Darjazi B B (2011), Comparison of volatile components of flower, leaf, peel and juice of 'Page' mandarin [(Citrus reticulata var 'Dancy' $\times$ Citrus paradisi var 'Duncan') $\times$ Citrusclementina], African J. of Biotech. 10(51): 10437-10446.

Fisher K and Phillips C (2008), Potential antimicrobial uses of essential oils in food: Is citrus the answer? ,Trends in Food Sci. Technol. 19: 156-164.

Ghulam M K, Ashraf M Y, Hussain A I, Andleeb S and Chughtai M I (2013), Antioxidant potential of peel essential oils of three Pakistani citrus species: citrus reticulata,citrus sinensis and citrus paradisii. Pak. J. Bot. 45(4): 1449-1454.

Lis-Balchin M, Hart S (1999), Studies on the mode of action of the essential oil of lavender (Lavandula angustifolia P. Miller), Phytother Res. 13(6): 540-2.

Marie-Laure L, Dominique R S, Felix T and Joseph C (2000), Chemical variability of peel and leaf essential oils of mandarins from Citrus reticulata Blanco, Biochem System Ecol. 28(1): 61-78.

Olusegun E, Oladapo B and Akinbo A (1990), Leaf volatile oil composition of Mandarin( Citrus reticulate) from Nigeria, J Ess Oil Res. 2(6): 329-220.

Raza H, Mumtaz-Khan M and Ali-Khan A (2003), Review: Seedlessness in Citrus, Int J Agri\& Biol. 5(3): 388-391. 
Rehman Z (2006), Citrus peel extract: A natural source of antioxidant, Food Chem. 99: 450-454.

Singh U, Wadhwani A M and Johri B M (1983), Dictionary of economic plants in India, 2nd Ed. Indian Council of Agricultural Research (ICAR), New Delhi, pp. 51-53.

Steuer B, Schulz H, Läger E (2001), Classification and analysis of citrus oils by NIR spectroscopy, Food Chem. 72(1): 113-117.

Sattar A (1989), Extraction and Processing Technology of Essential Oils, Proceeding $1^{\text {st }}$ National Symposium of Essential Oils, Perfumes Flav, pp. 7-10.

Saima S, Shabnam J, Shaista N, Zahida P, Rauf A K and Razia Khurram S(2012), Volatile components and antimicrobial activity of Citrus sinensis var. mosammi leaves oil, J. Med. Plants Res. 6(11): 2184-2187.
Shabnam J, Ayesha J, Shaista N, Saeed M K, Zaid M, Siddiqui S Z and Rauf A (2014), Phytochemistry, GC-MS Analysis, Antioxidant and Antimicrobial Potential of Essential Oil From Five Citrus Species, $J$. Agri Sci. 6(3): 201-208.

Ye W, Qin Y, Ye Z, Teixeria da Silva J A, Zhang L, Wu X, Lin S and Hu G (2009), Seedless Mechanism of a New Mandarin Cultivar 'Wuzishatangju' (Citrus Reticulata Blanco), Plant Sci. 177(1): 19-27.

Yamamoto M, Matsumoto R and Yamada Y (1995), Relationship between Sterility and Seedlessness in Citrus, J. Japanese Soc Horticultural Sci. 64(1): 23-29.

Received: 23 July 2013; Revised: 10 April 2014; Accepted: 03 June 2014. 